\title{
Thermodynamics of standing and lying behavior in lactating dairy cows in freestall and parlor holding pens during conditions of heat stress
}

\author{
K. V. Nordlund, ${ }^{*}$ P. Strassburg,† T. B. Bennett, G. R. Oetzel, and N. B. Cook \\ Department of Medical Sciences, School of Veterinary Medicine, University of Wisconsin-Madison 53706
}

\section{ABSTRACT}

Heat load is a challenge for high-producing dairy cows, with adverse consequences on production, reproduction, and welfare. The objectives of this observational study in 2 commercial dairy herds were to determine the effects of environmental heat stress on standing and lying behavior, to monitor the changes in core body temperature (CBT) of cows during lying and standing bouts, and to compare changes in CBT during standing bouts in freestall pens versus standing in holding pens. High-producing cows were selected for data collection over a period of $6 \mathrm{~d}$ of increasing heat stress during a heat wave to which they were not acclimated. A total of 20 cows were fitted with leg accelerometers that recorded lying behavior and with vaginal temperature loggers that recorded CBT. These data were recorded at 30-s intervals. Time in the parlor holding pen was calculated from automated parlor software that recorded milking unit attachment and removal times. Mean daily temperature-humidity index in the pens increased from 68.5 to 79.0 during the 6 -d trial, whereas mean daily lying time decreased from 9.5 to $6.2 \mathrm{~h} / \mathrm{d}$. The mean number of lying bouts per day remained similar at 11.1 to 12.2 , but duration of lying bouts decreased from a high of $49.7 \mathrm{~min}$ on the coolest day to $32.8 \mathrm{~min}$ on the hottest day. During lying bouts, CBT increased at a mean rate of $0.50^{\circ} \mathrm{C} / \mathrm{h}$. In contrast, $\mathrm{CBT}$ changed at a mean rate of $-0.25^{\circ} \mathrm{C} / \mathrm{h}$ when standing in the freestall pens and only $-0.09^{\circ} \mathrm{C} / \mathrm{h}$ when standing in the milkingcenter holding pens. Explanatory models for the CBT at which cows ended either standing or lying bouts were derived from 6 selected lying bouts and 3 selected standing bouts for each cow on each day. The CBT at which a cow ended a lying bout was positively related to $\mathrm{CBT}$ and temperature-humidity index at the start

Received October 22, 2018.

Accepted March 5, 2019.

*Corresponding author: ken.nordlund@wisc.edu

$\dagger$ Current address: Lodi Veterinary Care, 705 N. Main Street, Lodi, WI 53555. of the bout, bout duration, and rate of CBT change during the bout. The CBT at which a cow ended a standing bout was negatively related to bout duration and positively related to start CBT, start temperaturehumidity index, and rate of CBT change. Insights into the thermodynamics of standing and lying behavior in dairy cows during periods of heat stress provided by this study may contribute to the development of more effective strategies to mitigate heat load in dairy cattle. Key words: lactating cow, heat load, lying bout, standing bout, core body temperature

\section{INTRODUCTION}

Heat load is recognized as having a substantial negative economic effect on the US dairy industry (St-Pierre et al., 2003), realized largely through reduced milk yield (West, 2003); impaired reproductive performance (Jordan, 2003; Schüller et al., 2016); and other losses associated with impaired mammary tissue function (Tao et al., 2018), adverse effects on the developing fetus during late gestation (Dahl et al., 2016), and others (Collier et al., 2017). Polsky and von Keyserlingk (2017) summarized the coping strategies of dairy cows as physiological (to include increased respiration rate, panting, sweating, and reduced milk yield and reproductive function) and behavioral (to include increased water intake, reduced feed intake and shifting of feed intake to cooler periods of the day, shade seeking, reduced activity, and increased time spent standing). Further, some of these heat load coping strategies can become welfare issues, creating frustration, aggression, and pain associated with hunger, thirst, and lameness (Polsky and von Keyserlingk, 2017).

Increased standing, one of the behavioral strategies in response to heat load, exposes more surface area of the cow to potential cooling through convection, evaporation, and radiation (Allen et al., 2015). Multiple studies show that cows increase standing time during periods of heat stress with reciprocal reductions in lying time (Hillman et al., 2005; Cook et al., 2007; Allen et al., 2015). From the standpoint of the affective state of the cow, frustration, discomfort, and pain may occur 
when standing for heat dissipation frustrates a desire to lie down (Polsky and von Keyserlingk, 2017). Indeed, increased standing time increases the risk for lameness that may appear several months later (Leonard et al., 1996; Galindo et al., 2000; Proudfoot et al., 2010), making heat stress a likely factor driving a seasonal increase in lameness in the late summer (Cook et al., 2004). Interest in resting behavior has grown over recent years with the development of inexpensive data loggers, such that monitoring lying time has been suggested as a monitor for welfare audits of dairy cows (Vasseur et al., 2012; Vasseur et al., 2015). However, many factors have been identified that influence daily lying time, some intrinsic to the cow [e.g., parity, stage of lactation, daily milk production (Vasseur et al., 2015), lameness (Cook et al., 2004; Chapinal et al., 2009), and social rank within the group (Galindo and Broom, 2000)] and others dependent on housing and management practices. Housing and management factors that influence lying time include resting surfaces (Haley et al., 2000; Tucker et al., 2003; Cook et al., 2004), width of freestalls (Tucker et al., 2004), area of freestalls (Morabito et al., 2017), amount of bedding (Tucker and Weary, 2004; Drissler et al., 2005), moisture content of bedding, (Fregonesi et al., 2007b), and degree of overstocking in the pen (Fregonesi et al., 2007a). We know that heat stress modifies resting behavior at around a temperature-humidity index (THI) of 68 (Cook et al., 2007; Allen et al., 2015), and it would be wise to make some additional accommodations for environmental conditions on the day of a welfare audit if lying time is to be used as an outcome. Presently, no guidelines exist because remarkably few studies have examined the thermodynamics of core body temperature (CBT) of dairy cows while standing or lying under heat stress conditions. Reports by Hillman et al. (2005) and Allen et al. (2015) show that cows dissipate CBT while standing but increase CBT while lying down during heat stress conditions. Hillman et al. (2005) hypothesized that cows end a lying bout and stand to seek cooling when CBT reaches $38.9^{\circ} \mathrm{C}$. Allen et al. (2015) expanded on this threshold concept and reported a $50 \%$ likelihood of a cow standing at a $\mathrm{CBT}$ of $38.9^{\circ} \mathrm{C}$ but showed temperature variations of this threshold at different study locations and barn types. The behavioral decision to stand would likely be influenced by a variety of factors beyond CBT and could include hunger, thirst, various social interaction factors, interruptions by dairy farm personnel, and musculoskeletal discomfort from lying in one position for extended periods of time.

Collier et al. (2006) hypothesized that the holding pen was the location where dairy cows experience the greatest heat stress on a dairy. Other studies have found significant differences in THI between locations within a single dairy facility (Schüller et al., 2013; Schüller and Heuwieser, 2016), and THI was greatest in holding pens as measured by instruments suspended from neck chains of the cows (Schüller and Heuwieser, 2016). Although these studies suggest that holding pens are a particular site for heat stress, we are not aware of studies that report the effects of the holding pen microenvironment on the CBT of dairy cows.

Hillman et al. (2005) compared rate of dissipation of CBT while standing under sprinklers with fans versus standing under fans alone, but to our knowledge, no studies have measured CBT thermodynamics of cows standing in holding pens or made comparisons with standing in other locations within the barn.

This observational study had 2 units of interest: the cow and the barn location. Our objectives at the cow level were to examine the thermodynamics in heatstressed dairy cattle while lying and standing and to develop explanatory models regarding the CBT at which cows terminate those bouts under heat stress conditions. Our objective at the barn location level was to compare differences in the cow's ability to manage heat load while standing either in freestall pens or in the holding pens of modern confinement dairy facilities.

\section{MATERIALS AND METHODS}

\section{Facilities}

This trial was conducted at 2 similar dairy farms located $6 \mathrm{~km}$ apart in northeastern Wisconsin. Farm A was a 3,200-cow facility built in 2001, and farm B was a 3,600 -cow facility built in 2006. Both farms were managed under the same ownership. The adult cow facilities on both sites consisted of 3 parallel barns oriented east to west with a milking center located near the center and south of the barns. All barns had a center drivethrough feed alley with 2-row head-to-head oriented freestalls on each side. The freestall pens, excluding the drive-through feed alley, provided $6.5 \mathrm{~m}^{2}$ of area per cow. The freestalls on both dairy farms had identical dimensions (width of $1.17 \mathrm{~m}$ and length of $2.4 \mathrm{~m}$ ). All freestalls were deep bedded with recycled manure solids from a methane digester. Pen heat abatement equipment was similar on both farms with a water sprinkler system located over the feed line directed toward the backs of feeding cows and a single row of 0.91-m panel fans located at intervals of $12.5 \mathrm{~m}$ above and angled toward the freestalls. The 2-stage water sprinklers were activated to $30 \mathrm{~s}$ on and $10 \mathrm{~min}$ off at $21.1^{\circ} \mathrm{C}$. At $26.7^{\circ} \mathrm{C}$, the sprinklers changed to $30 \mathrm{~s}$ on and 5 min off. Half of the fans were activated at $13^{\circ} \mathrm{C}$, and all were engaged at 
$21^{\circ} \mathrm{C}$. The barns were naturally ventilated with retractable curtain sidewalls and open ridges of similar dimensions. Milking centers on both dairies were equipped with 80-cow rotary carousel parlors, and parlor holding pens on both sites were similar in size, providing $2 \mathrm{~m}^{2}$ of space per cow at maximum fill. Both holding pens were equipped with water soakers and fans, with soakers activated on the same schedule as at the feed line in the freestall pens. The holding pen at farm A was equipped with 34 panel fans arranged in 6 rows and angled downward toward the rear of the holding pen. The combination of fans were rated to move $1,700 \mathrm{~m}^{3} / \mathrm{h}$ per cow, which is consistent with traditional guidelines for holding pens (Smith et al., 2006). The holding pen at farm B was similar except that the fans nearest the parlor (25\% of the total fans) were positive pressure fans connected to distribution tubes as described by Mondaca et al. (2013a).

Study cows on both farms were housed in a single pen located on the south side of the east half of the northern-most barn. The pen at farm A had a mean (range) of 383 (381-385) cows during the study period, and the pen at farm B had 421 (418-424) cows. The pens on both dairies were stocked at a rate of 1.21 cows per freestall during the trial period. The distance between the parlor holding pen and entrance to the freestall pens was approximately $120 \mathrm{~m}$ at both sites.

\section{Cows}

Cows were enrolled from the 2 herds of Holstein-breed cows. All cows came from pens containing multiparous, high milk yielding, and nonpregnant animals. Cows were fed a TMR diet formulated to meet the nutrient requirements of lactating dairy cows twice daily (NRC, 2001) and were milked 3 times daily at approximately 0300, 1100, and $1900 \mathrm{~h}$.

\section{Animal-Based Measures}

All procedures were approved by the Animal Care and Use Committee of the Research Animal Resource Center at the University of Wisconsin-Madison. After all study cows had acclimated to the pen for at least 2 wk, data loggers were applied the day before the study onset. Standing and lying status was calculated from activity data loggers (HOBO Pendant G Acceleration Data Loggers, Onset Computer Corporation, Bourne, MA). The data loggers were taped to the lateral side of the limb above the metatarsophalangeal region of the right rear leg using a bandaging wrap (VetRap, 3M Animal Care Products, St Paul, MN). The loggers recorded the angle of the leg on 3 axes every $30 \mathrm{~s}$.
Excel (Microsoft Corporation, Redmond, WA) macros were used to edit and summarize the activity data to yield bout duration ( $\mathrm{min} /$ bout), lying bout frequency (bout/d), and total lying time (h/d), using the methodologies described by Ito et al. (2009) and adapted by Ledgerwood et al. (2010).

Vaginal temperature was recorded at 30-s intervals using calibrated temperature loggers (HOBO U12 Stainless Temperature Data Logger, Onset Computer Corporation) that were fitted to blank controlled intravaginal drug-release (CIDR) cattle inserts (Zoetis, Florham Park, NJ). The loggers measured temperature from -40 to $+125^{\circ} \mathrm{C}$ with an accuracy of $\pm 0.25^{\circ} \mathrm{C}$ from 0 to $+50^{\circ} \mathrm{C}$ and a resolution of $\pm 0.03^{\circ} \mathrm{C}$. Vaginal temperature has previously been validated as a marker of CBT (Vickers et al., 2010).

Automated parlor software (DairyPlan C21, GEA Farm Technologies, Naperville, IL) and on-farm DairyComp 305 (Valley Ag Software, Tulare, CA) herd management software provided individual cow data for the time of milker unit attachment, time of removal, and milk weight for each milking. Milking time data were used to calculate time spent in the parlor holding pen.

Cows selected for the study (30 total cows, 15 per herd) were matched between the 2 farms on the basis of parity, DIM, and milk yield at the start of the recording period. A total of 10 cows were lost from the study, 3 cows due to expulsion and loss of the temperature logger and CIDR, 1 cow due to failure of the Pendant G activity logger, and 6 cows due to subnormal, nonphysiological CBT of $\leq 37.4^{\circ} \mathrm{C}$. Vickers et al. (2010) suggest subnormal temperature readings may occur if the logger device protrudes from the vagina and is exposed to ambient temperatures. In addition, 5 of the cows experienced estrus during the trial; data from those cows were removed for the 24 -h period during which estrus was observed.

The final 20 cows included in the study were evenly distributed between the 2 farms. All were second-parity Holstein cows. The mean (range) DIM of the cows was 64 (59 to 68 ) and mean (range) daily milk yield was 52 (41 to 63$) \mathrm{kg} / \mathrm{d}$.

\section{Weather and Facility-Based Measures}

The trial period was selected based on a weather forecast (www.wunderground.com) predicting daytime and nighttime temperatures exceeding 29.4 and $18.3^{\circ} \mathrm{C}$, respectively. Weather data were collected daily from a local weather station that recorded outdoor temperature, relative humidity, and wind speed and direction. Indoor ambient temperature and relative humidity were recorded every $30 \mathrm{~s}$ using electronic loggers (HOBO Pro 


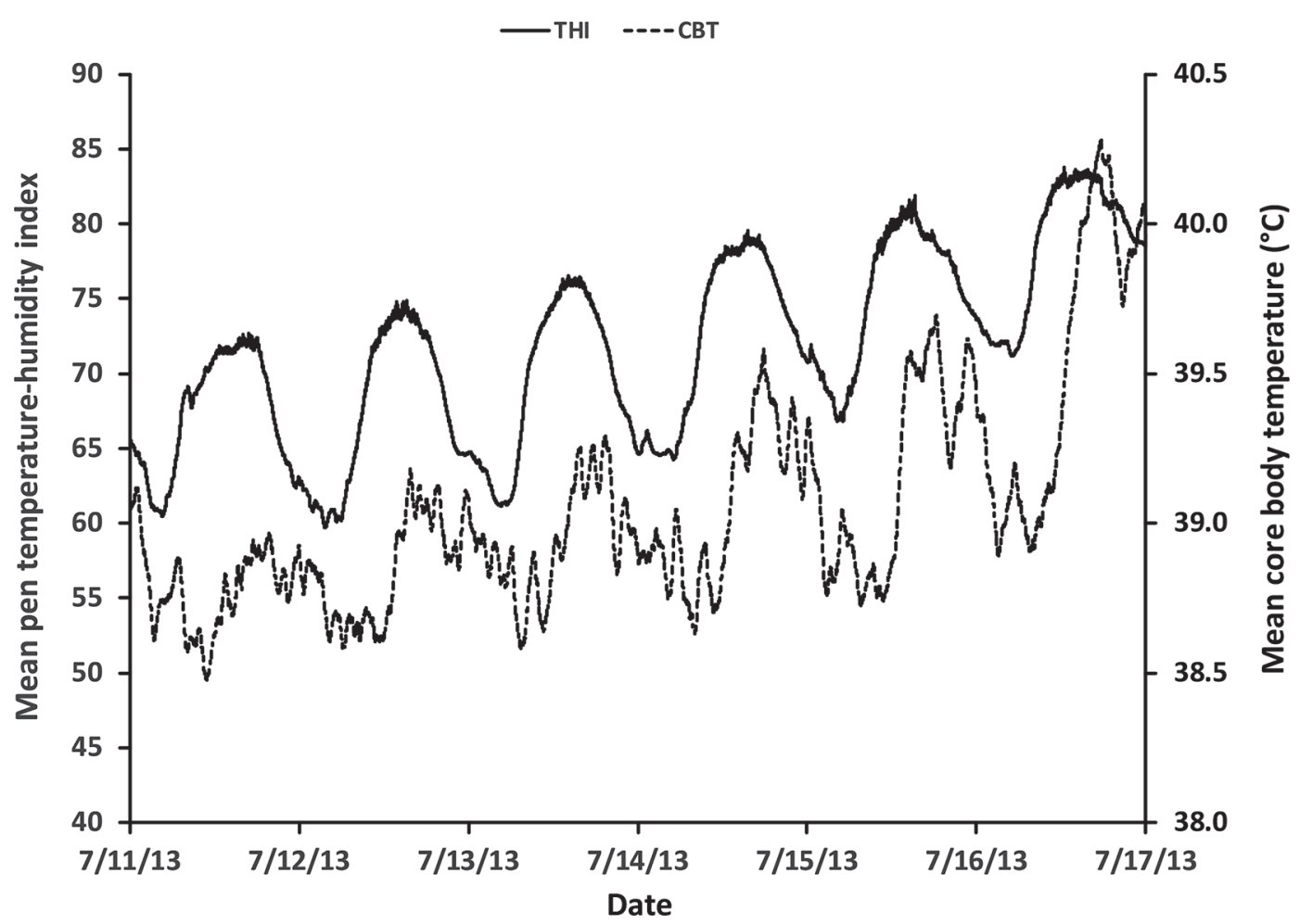

Figure 1. Mean pen temperature-humidity index (THI) and mean core body temperature (CBT) for 20 cows from 2 Holstein herds during $6 \mathrm{~d}$ of increasing heat stress.

v2 Temperature/RH Data Logger, Onset Computer Corporation) at both farms. These loggers measured temperature from -40 to $+70^{\circ} \mathrm{C}$ with an accuracy of $\pm 0.21^{\circ} \mathrm{C}$ from 0 to $+50^{\circ} \mathrm{C}$ and a resolution of $\pm 0.02^{\circ} \mathrm{C}$ and relative humidity from 0 to $100 \%$ at -40 to $+70^{\circ} \mathrm{C}$ with an accuracy of $\pm 2.5 \%$ from 10 to $90 \%$ and a resolution of $0.03 \%$. The temperature and humidity loggers were located above the entrance and exit lanes of the milking parlor, above each side of the parlor holding pen, and at both ends and the middle of the freestall pen where the trial cows were housed. The loggers were calibrated and synchronized before placement. All loggers were in place by midday on July 10, 2013, and were removed by midday on July 17, 2013. This yielded data for 6 complete days from July 11 through July 16, 2013.

Temperature and relative humidity $(\mathrm{RH})$ data were converted to THI values using the equation THI = $\left(1.8 \times T_{\mathrm{db}}+32\right)-[(0.55-0.0055 \times \mathrm{RH}) \times(1.8 \times$ $\left.\left.T_{\mathrm{db}}-26\right)\right]$, where $T_{\mathrm{db}}$ is dry-bulb temperature in ${ }^{\circ} \mathrm{C}$, (NRC, 1971; Bohmanova et al., 2007). The ambient temperature increased each day through the trial period. Mean THI and CBT are shown for each recorded day in Figure 1. The weather through the trial period developed into a heat wave to which the cows were not acclimated. The THI values for d 5 and 6 had not been reached previously that year, and THI on d 4 had been equaled on only $5 \mathrm{~d}$ over the preceding month. Traditional THI interpretive guidelines developed by Armstrong (1994) suggested THI $\geq 72$ as the heat stress threshold for dairy cows; however, other workers, including those by Cook et al. (2007), Collier et al. (2011), and Allen et al. (2015), reported signs of heat stress beginning at THI $\geq 68$. Using the threshold of THI $\geq 68$, the study cows were subjected to a few hours of heat stress on the first day, followed by increasing hours each day and terminating in a final day entirely above the heat stress threshold. Average CBT of the subject cows followed a similar pattern (Figure 1). The normal values of CBT of dairy cattle range between 38.0 and $39.0^{\circ} \mathrm{C}$ (Terra and Reynolds, 2014); average CBT exceeded that range for a few hours on the first day and increased each day. Study cows experienced hyperthermia $\left(>39.0^{\circ} \mathrm{C}\right)$ for almost the entire last day of the trial.

\section{Statistical Analysis}

To obtain approximately equal numbers of bouts across all cows in the freestall pens, only the first 2 lying bouts after each milking were selected for further analysis, along with the standing bout between the 2 ly- 
ing bouts. Although the average cow was recorded with 3.6 lying bouts between each milking, occasionally, cows only had a single lying bout in the interval. No lying bouts were recorded in the holding pen. Standing bouts in the holding pen were determined using the recorded milking times from parlor software for each cow and matched to activity data logger data. Entrance into the holding pen was estimated as a default value for all cows in the pen as the time of milking unit attachment to the first cow from the group. Departure from the holding pen into the parlor was represented as the time of milking unit attachment to the individual study cow. Duration of time in the holding pen was calculated by subtracting the entrance time from the exit time. Most of the cows had arrived in the holding pen several minutes before the closure of the rear gate and the first pen mate entering the rotary milker. Although the method does not capture all of the time cows spent in the holding pen, the analyzed holding pen data reflect time in the holding pen. This method served our needs because the item of interest was dissipation of CBT by cows standing in the holding pen, not the precise time that cows spent there. This is another example of the creative use of data from electronic dairy equipment for purposes different from those for which the equipment was originally designed (Thompson et al., 2017).

Descriptive data were compiled for each lying and standing bout; these included start CBT $\left({ }^{\circ} \mathrm{C}\right)$, end $\mathrm{CBT}$ $\left({ }^{\circ} \mathrm{C}\right)$, start THI, end THI, bout duration (min), and bout rate of CBT change $\left({ }^{\circ} \mathrm{C} / \mathrm{h}\right)$. Correlations between variables were examined in PROC CORR for each outcome. No variables were highly correlated $(\mathrm{r}<0.8)$, and all were eligible for inclusion in the models. Outcome variables were CBT at the end of a lying bout and CBT at the end of a standing bout in a freestall. Standing bouts in the holding pen were not modeled because the start and end circumstances of these bouts were determined by nonenvironmental factors such as time of the start of milking and parlor throughput. Explanatory variables considered were CBT and THI at the start of the bout, duration of the bout, and rate of CBT change during the bout. These variables were initially screened by visual inspection of scatterplots and by $t$-tests of means for the effects of herd, day, milking number preceding the bout, and cow. No substantial differences existed between lying bouts before different milkings or between herds that could not best be explained by changes in environmental circumstance (reflected by change in THI). Therefore, milking number and herd were not offered for inclusion in the explanatory models. However, substantial differences were noted by cow. This confirmed that individual cow effects beyond the matching variables (parity, DIM, and milk yield) should be accounted for in the explanatory models.
The Mixed Procedure of SAS (SAS version 9.4; SAS Institute Inc., Cary, NC) was used to examine the relationship between the outcome and explanatory variables described previously. For each outcome, a model statement was tested for each predictor variable, one at a time, allowing for random slope and random intercept to account for variability between cows. A model accounting for a random intercept with a repeated statement for cow and an unstructured covariance structure was compared with a model accounting for random intercept and random slope for each predictor using Akaike's information criterion. A final model was created for end CBT accounting for random intercepts and random slopes where appropriate, based on the magnitude of the Akaike's information criterion, with explanatory variables included if they were $P<0.05$. Plots of residuals were inspected for evidence of heteroscedasticity. No evidence was found, and no data transformations were applied.

Predicted values from the explanatory models were calculated across a range of values for THI and compared with observed values. Additionally, the 10th and 90th percentiles of explanatory variables were determined and used to determine the range of the effect of each explanatory variable on the modeled outcome. The ranges were plotted in rank order as tornado diagrams that depict the relative sensitivity of the outcome variable to changes in the explanatory variables.

\section{RESULTS}

\section{Resting Behavior}

Mean \pm SE daily lying time decreased from $9.5 \pm 0.4$ $\mathrm{h} / \mathrm{d}$ to $6.2 \pm 0.4 \mathrm{~h} / \mathrm{d}$ over the study as mean daily pen THI increased from 68.5 to 79.0 (Figure 2). Changes in daily lying time between $\mathrm{d} 1$ and 3 were different $(P<$ $0.05)$ from d 5 and 6 of the study, and d 4 was different $(P<0.05)$ from $\mathrm{d} 1$ and 6 . Mean $\pm \mathrm{SE}$ number of lying bouts ranged from $11.1 \pm 0.7$ per day to $12.2 \pm 1.0$ per day across days and were not different between days $(P$ $>0.05$ ). Lying bout duration decreased from a high of $49.7 \pm 3.6 \mathrm{~min} / \mathrm{d}$ on $\mathrm{d} 2$ to a low of $32.8 \pm 2.2 \mathrm{~min} / \mathrm{d}$ on the last day. Significant differences in lying bout duration between days mirrored the pattern observed for daily lying time.

\section{Standing and Resting Thermodynamics and Bout Duration}

Mean \pm SE CBT of cows increased at a rate of 0.50 $\pm 0.02^{\circ} \mathrm{C} / \mathrm{h}$ when lying and decreased at $-0.25 \pm$ $0.03^{\circ} \mathrm{C} / \mathrm{h}$ when standing in the freestall pen; these rates were different $(P<0.001)$. Cow CBT decreased at a 


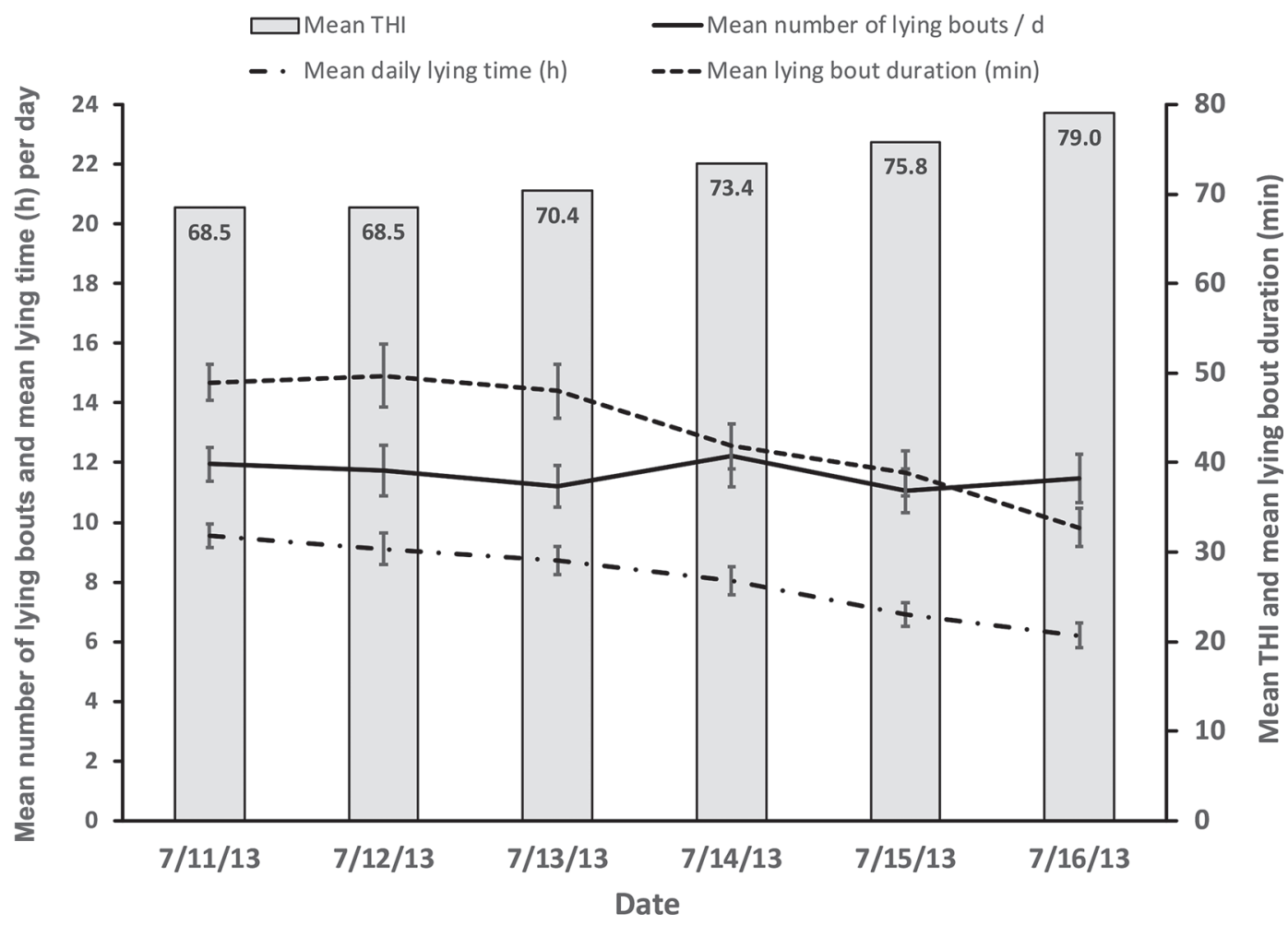

Figure 2. Mean daily temperature-humidity index (THI) and mean \pm SE daily lying time, number of daily lying bouts, and daily mean duration of lying bouts from 20 cows in 2 Holstein herds during $6 \mathrm{~d}$ of increasing heat stress.

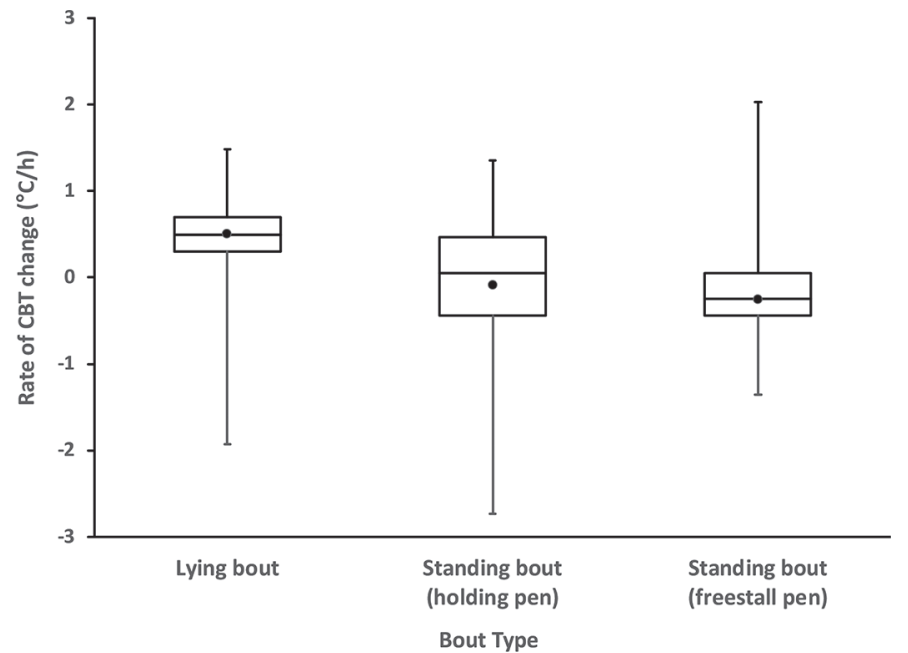

Figure 3. Boxplot of the mean rate of core body temperature (CBT) change $\left({ }^{\circ} \mathrm{C} / \mathrm{h}\right)$ for 20 cows in 2 Holstein herds during $6 \mathrm{~d}$ of increasing heat stress. Rates are presented for lying bouts $(\mathrm{n}=670)$, standing bouts in the holding pen $(\mathrm{n}=295)$, and standing bouts in the freestall pen $(\mathrm{n}=329)$. The centerline within a box represents the median, the dot within a box represents the mean, the box perimeter delineates the interquartile range (IQR), and the whiskers of the box extend $1.5 \times$ the IQR. All rates were different $(P<0.001)$. rate of $-0.09 \pm 0.05^{\circ} \mathrm{C} / \mathrm{h}$ while standing in the holding pens compared with standing in the freestall pens, which was significantly lower at $P<0.001$ (Figure 3 ).

Mean \pm SE CBT at the end of a lying bout was 39.2 $\pm 0.02^{\circ} \mathrm{C}$. Mean $\pm \mathrm{SE}$ values for variables that were modeled to explain this outcome were start of lying bout CBT $\left(38.8 \pm 0.02^{\circ} \mathrm{C}\right)$, start of lying bout THI $(71.2 \pm 0.25)$, lying bout duration $(49.8 \pm 1.1 \mathrm{~min})$, and $\mathrm{CBT}$ rate of change during the lying bout $(0.50$ $\left.\pm 0.02^{\circ} \mathrm{C} / \mathrm{h}\right)$. The explanatory model for the CBT at which cows terminate their lying bouts by rising is presented in Table 1. All 4 possible explanatory variables were included in the final model at $P<0.001$, and all were positively associated with CBT at the end of a lying bout. Sensitivity analysis based on the 10th and 90th percentiles of each explanatory variable demonstrated that start CBT exerted the strongest influence on predicted CBT at the end of a lying bout (Figure 4).

Table 2 compares explanatory model predictions of lying bout end CBT with observed results for THI categories between THI 60 and THI 85. Each THI category summarized observed lying bouts that started at that THI \pm 2.5 . The model for CBT at the end of a lying bout almost perfectly predicted mean CBT at the end of a lying bout for each THI category. The CBT at which cows ended their lying bouts was not 
Table 1. Outcome of mixed model to estimate the core body temperature (CBT) at the end of a lying bout with regression estimates (SE) for each variable, df, $F$-values, and $P$-values for type III sum of squares

\begin{tabular}{lccrrc}
\hline Variable & Estimate & $\mathrm{SE}$ & $\mathrm{df}$ & $F$-value & $P$-value \\
\hline Intercept & 4.530 & 0.558 & 19 & - & - \\
Start CBT $\left({ }^{\circ} \mathrm{C}\right)$ & 0.869 & 0.015 & 608 & $3,414.0$ & $<0.001$ \\
Start THI & 0.007 & 0.001 & 19 & 31.6 & $<0.001$ \\
Bout duration $(\mathrm{min})$ & 0.006 & 0.0005 & 19 & 171.5 & $<0.001$ \\
Bout rate of CBT change $\left({ }^{\circ} \mathrm{C} / \mathrm{h}\right)$ & 0.455 & 0.015 & 608 & 901.3 & $<0.001$ \\
\hline
\end{tabular}

${ }^{1} \mathrm{THI}=$ temperature-humidity index.

static; it increased from mean $\pm \mathrm{SE}$ of $39.0 \pm 0.04^{\circ} \mathrm{C}$ for the lowest THI category (THI 60) to $39.6 \pm 0.09^{\circ} \mathrm{C}$ for the highest THI category (THI 85). The mean \pm SE duration of lying bouts decreased from $70.5 \pm 4.1$ $\min$ for the THI 60 category to $28.7 \pm 3.3 \mathrm{~min}$ for the highest THI category. Mean temperature gain in CBT during lying bouts was rather consistent (range of 0.40 to $0.48^{\circ} \mathrm{C}$ ) across the span of THI categories. Rate of $\mathrm{CBT}$ change increased from mean $\pm \mathrm{SE}$ of $0.28 \pm$ $0.04^{\circ} \mathrm{C} / \mathrm{h}$ for the THI 60 category to $0.76 \pm 0.1^{\circ} \mathrm{C} / \mathrm{h}$ for the THI 85 category.

Mean $\pm \mathrm{SE} \mathrm{CBT}$ at the end of a standing bout in a freestall pen was $38.9 \pm 0.03^{\circ} \mathrm{C}$. Mean $\pm \mathrm{SE}$ values for variables that were modeled to explain this outcome were start of standing bout CBT $\left(39.2 \pm 0.02^{\circ} \mathrm{C}\right)$, start of standing bout THI $(71.3 \pm 0.37)$, standing bout duration $(67.0 \pm 2.9 \mathrm{~min})$, and $\mathrm{CBT}$ rate of change during a standing bout $\left(-0.25 \pm 0.03^{\circ} \mathrm{C} / \mathrm{h}\right)$. The explanatory model for the CBT at which cows terminate their standing bouts by lying down is presented in Table 3 . All 4 possible explanatory variables were included in the final model at $P<0.01$. Start CBT, start THI, and rate of CBT change during a standing bout were positively associated with CBT at the end of a lying bout. The duration of the standing bout was negatively associated with the CBT at the end of the standing bout. Sensitivity analysis based on the 10th and 90th percentiles of each explanatory variable demonstrated that start CBT exerted the strongest influence on predicted CBT at the end of a standing bout (Figure 5).

Table 4 compares explanatory model predictions of standing bout end CBT with observed results for THI categories between THI 60 and THI 85. The model for $\mathrm{CBT}$ at the end of a standing bout very closely pre-

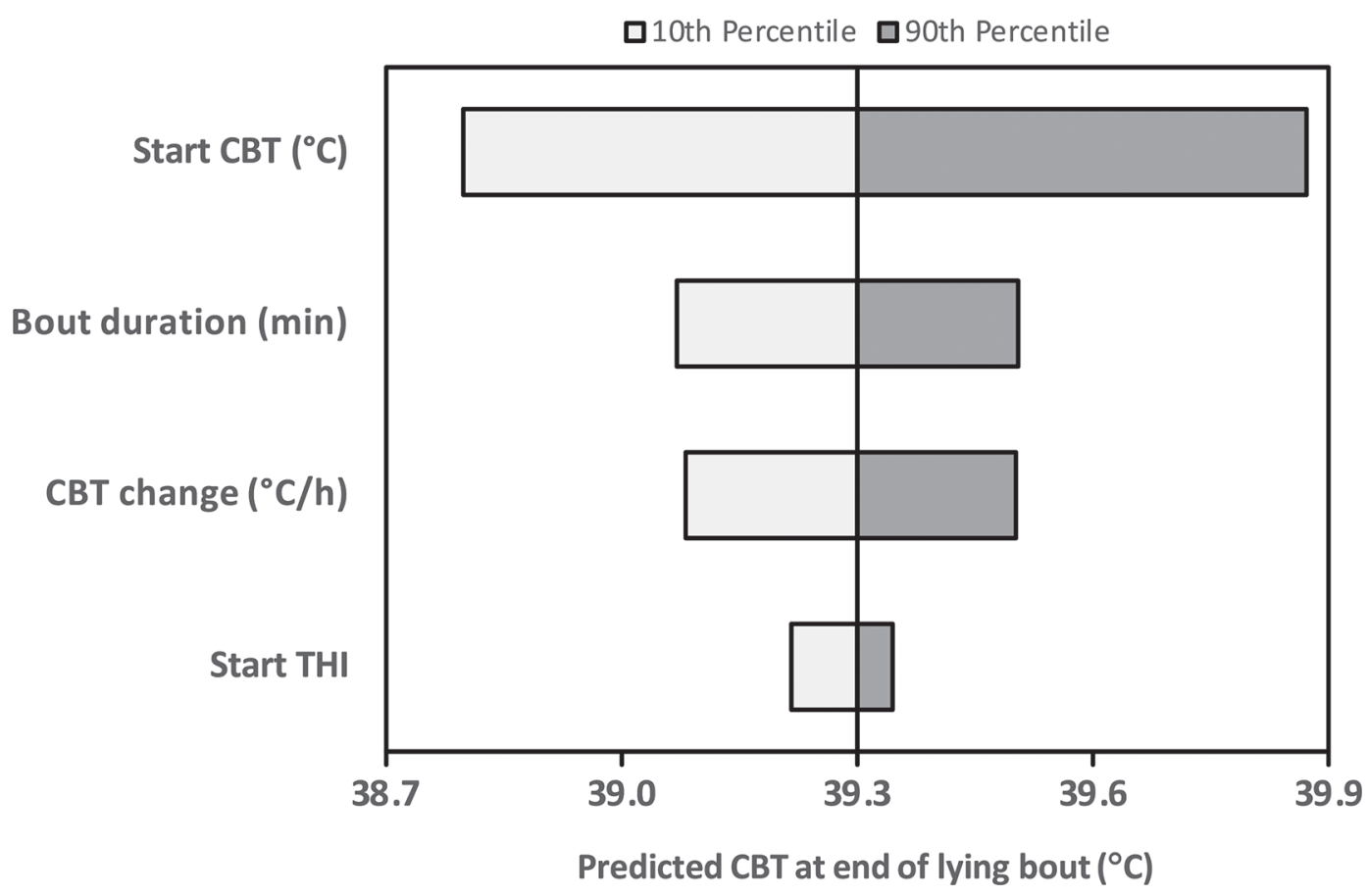

Figure 4. Tornado diagram of the sensitivity analysis for variables used to predict core body temperature (CBT) at the end of a lying bout. THI = temperature-humidity index. Data are from 670 lying bouts of 20 cows from 2 Holstein herds during $6 \mathrm{~d}$ of increasing heat stress. 
Table 2. Observed mean ( $\pm \mathrm{SE}$ ) lying-bout core body temperature (CBT) data and lying-bout duration by temperature-humidity index (THI) category compared with model prediction for CBT at the end of a lying bout

\begin{tabular}{|c|c|c|c|c|c|c|c|}
\hline $\begin{array}{l}\text { THI }( \pm 2.5) \\
\text { categories at start } \\
\text { of lying bout }\end{array}$ & $\mathrm{N}$ & $\begin{array}{c}\text { Observed } \\
\text { start CBT } \\
\quad\left({ }^{\circ} \mathrm{C}\right)\end{array}$ & $\begin{array}{l}\text { Observed } \\
\text { end CBT } \\
\quad\left({ }^{\circ} \mathrm{C}\right)\end{array}$ & $\begin{array}{l}\text { Model- } \\
\text { predicted end } \\
\text { CBT }\left({ }^{\circ} \mathrm{C}\right)\end{array}$ & $\begin{array}{l}\text { Observed lying- } \\
\text { bout duration } \\
\text { (min) }\end{array}$ & $\begin{array}{l}\text { Observed bout } \\
\text { rate of CBT } \\
\text { change }\left({ }^{\circ} \mathrm{C} / \mathrm{h}\right)\end{array}$ & $\begin{array}{l}\text { Observed net } \\
\text { change of lying- } \\
\text { bout CBT }\left({ }^{\circ} \mathrm{C}\right)\end{array}$ \\
\hline 60 & 91 & $38.6(0.04)$ & $39.0(0.04)$ & 39.0 & $70.5(4.1)$ & $0.28(0.04)$ & 0.40 \\
\hline 65 & 123 & $38.6(0.03)$ & $39.1(0.03)$ & 39.1 & $56.3(2.6)$ & $0.43(0.03)$ & 0.44 \\
\hline 70 & 160 & $38.7(0.03)$ & $39.1(0.03)$ & 39.1 & $53.1(2.1)$ & $0.46(0.03)$ & 0.45 \\
\hline 75 & 146 & $38.8(0.04)$ & $39.3(0.04)$ & 39.3 & $44.2(2.0)$ & $0.58(0.04)$ & 0.48 \\
\hline 80 & 124 & $39.2(0.05)$ & $39.6(0.04)$ & 39.6 & $35.2(1.8)$ & $0.63(0.03)$ & 0.40 \\
\hline 85 & 26 & $39.2(0.10)$ & $39.6(0.09)$ & 39.7 & $28.7(3.3)$ & $0.76(0.09)$ & 0.40 \\
\hline
\end{tabular}

dicted observed mean CBT at the end of a standing bout for each THI category. The range of CBT when cows ended a standing bout (mean $\pm \mathrm{SE}$ of $38.6 \pm$ $0.06^{\circ} \mathrm{C}$ to $39.4 \pm 0.15^{\circ} \mathrm{C}$ ) overlapped the range of $\mathrm{CBT}$ when cows ended a lying bout $\left(38.6 \pm 0.04^{\circ} \mathrm{C}\right.$ to $39.2 \pm$ $0.1^{\circ} \mathrm{C}$ ) as shown in Table 2.

Of significance was the fact that cows did not dissipate heat while standing at higher THI; instead, CBT increased $0.001^{\circ} \mathrm{C} / \mathrm{h}$ for the THI 80 category and $0.21^{\circ} \mathrm{C} / \mathrm{h}$ for the THI 85 category. In contrast, net changes in CBT for standing bouts in the lower 4 THI categories resulted in net $\mathrm{CBT}$ changes between -0.38 and $-0.46^{\circ} \mathrm{C}$ per bout.

\section{DISCUSSION}

This study examined the thermodynamics of standing and lying behavior in a group of lactating dairy cows housed in 2 similarly designed facilities during a period of acute heat stress in Wisconsin. The 6-d period of the study, during which THI increased each day and resulted in prolonged periods of hyperthermia, provided a unique opportunity to make this assessment. We examined the differences in duration and thermoregulatory responses associated with lying and standing bouts, and we compared differences in the ability to handle heat loads while standing in the freestall pen

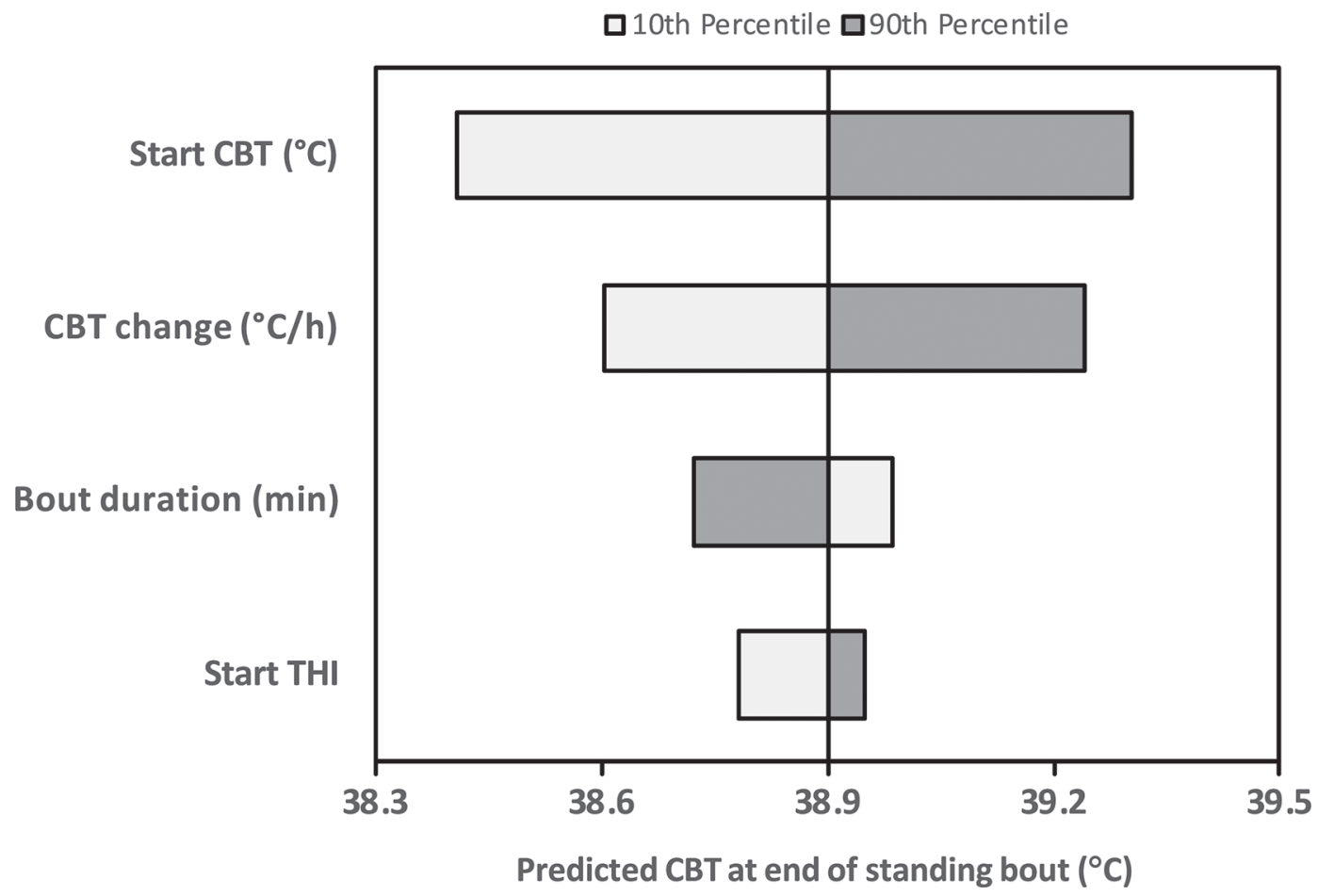

Figure 5. Tornado diagram of the sensitivity analysis for variables used to predict core body temperature (CBT) at the end of standing bouts in a freestall pen. THI = temperature-humidity index. Data are from 329 standing bouts of 20 cows from 2 Holstein herds during 6 d of increasing heat stress. 
Table 3. Outcome of mixed model to estimate the core body temperature (CBT) at the end of a standing bout in a freestall pen with regression estimates (SE) for each variable, df, $F$-values, and $P$-values for type III sum of squares

\begin{tabular}{lrrrrr}
\hline Variable & Estimate & SE & df & $F$-value & $P$-value \\
\hline Intercept & 6.589 & 1.428 & 19 & - & - \\
Start CBT $\left({ }^{\circ} \mathrm{C}\right)$ & 0.813 & 0.038 & 19 & 453.1 & $<0.001$ \\
Start THI & 0.009 & 0.002 & 248 & 21.5 & $<0.001$ \\
Standing bout duration $(\mathrm{min})$ & -0.002 & 0.0006 & 19 & 12.1 & 0.003 \\
Bout rate of CBT change $\left({ }^{\circ} \mathrm{C} / \mathrm{h}\right)$ & 0.506 & 0.047 & 19 & 115.4 & $<0.001$ \\
\hline
\end{tabular}

${ }^{1} \mathrm{THI}=$ temperature-humidity index.

versus the holding pen. We also examined the suggestion put forward by previous workers that cows are likely to stand and seek cooling when their CBT reaches $38.9^{\circ} \mathrm{C}$ (Hillman et al., 2005; Allen et al., 2015).

\section{Lying Time and Number and Duration of Lying Bouts per Day}

Mean daily lying times of less than $9.5 \mathrm{~h} / \mathrm{d}$ observed in the current study are less than times typically reported from freestall barns in multiherd surveys (Ito et al., 2009: 11 h/d; von Keyserlingk et al., 2012: 11 h/d; Solano et al., 2016: 10.6 h/d). Gomez and Cook (2010) reported $11.9 \mathrm{~h} / \mathrm{d}$ from $16 \mathrm{Wisconsin}$ dairies but excluded data from days where the mean daily temperature exceeded $18.3^{\circ} \mathrm{C}$. However, the reduced lying times in our study are consistent with those from Cook et al. (2007), who found mean lying times of 7.9 to 9.1 $\mathrm{h} / \mathrm{d}$ during periods of moderate heat stress. These findings emphasize the profound reductions in lying times that occur during heat stress.

The current study permitted a further examination of resting behavior changes under conditions of a rapid increase in THI. Whereas the lying time decreased each day from $9.5 \mathrm{~h} / \mathrm{d}$ on the most moderate day to $6.2 \mathrm{~h} / \mathrm{d}$ on the hottest day, the number of daily lying bouts remained relatively constant (no statistically significant changes) at approximately $11.7 / \mathrm{d}$. The change in daily lying time was related to a significant decline in the mean duration of lying bouts from 49 min per bout on the coolest day to $33 \mathrm{~min}$ per bout on the hottest day.
The number of bouts per day are consistent with other freestall studies, but bout durations in this study were less than those typically recorded under more moderate temperature conditions (Gomez and Cook, 2010: 12.9 bouts per day, 96 min per bout; Vasseur et al., 2012: 10-11 bouts per day, 70-75 min per bout; Solano et al., 2016: 10.2 bouts per day, 63 min per bout). Unlike the relatively longer lying bout durations found under moderate temperature conditions, Allen et al. (2015) found lying bouts of 48 to 60 min per bout under mild to moderate heat stress. These were consistent with our findings, despite the exclusion of bouts shorter than 20 min from their data set.

If lying behavior measures are to be used in welfare assessments, accommodations should be made for the effect of THI. A linear regression of our data showed that each increasing unit of mean daily THI was associated with a reduction of the mean daily lying time by $18.1 \mathrm{~min}$.

\section{Lying Thermodynamics}

The motivations for cows to terminate a lying bout by standing up under conditions of heat stress have received little attention. The behavioral decision could be affected by any number of parameters such as hunger, discomfort from lying on one side too long, disruptions from dairy personnel or other animals, and other factors. We believe that hunger and personnel disruptions were minimized in our study by selecting the first 2 lying bouts following a return from milking.

Table 4. Observed mean $( \pm \mathrm{SE})$ core body temperature $(\mathrm{CBT})$ at the end of a standing bout in a freestall pen and duration of standing bouts in a freestall pen by temperature-humidity index (THI) category compared with model prediction for CBT at the end of standing bouts

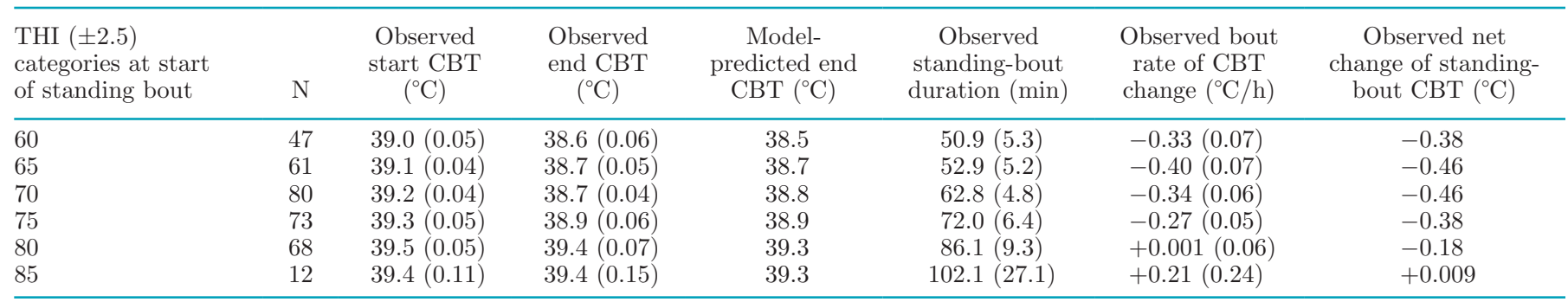


At this time, most cows will have spent time at the feed bunk before lying down (Mentink and Cook, 2006) and most will have completed the second bout several hours before the next milking based on our data. Hillman et al. (2005) advanced a hypothesis of a threshold CBT where cows will stand to try to dissipate heat and suggested the point was $38.9^{\circ} \mathrm{C}$. Allen et al. (2015) noted that a $\mathrm{CBT}$ of $38.9^{\circ} \mathrm{C}$ marked a $50 \%$ likelihood that a cow would be standing rather than lying down. Our models (Tables 1 and 4) suggest a more complex situation in which CBT at the end of either a lying or standing bout is related to ambient THI, CBT of the cow at the start of the bout, duration of the bout, and rate of CBT change. Our data indicate that cows end their lying bouts between 39.0 and $39.6^{\circ} \mathrm{C}$, which is slightly higher than the threshold proposed by Hillman et al. (2005) and Allen et al. (2015). The CBT range in which cows rise to end a lying bout overlaps the CBT range in which cows choose to lie down $\left(38.6\right.$ to $\left.39.2^{\circ} \mathrm{C}\right)$. This challenges the idea of an absolute temperature threshold that determines whether a cow stands or lies down. Clearly, the likelihood that a cow rises increases with ambient THI, as demonstrated by Allen et al. (2015). Of interest in the current study is the finding that cows ended lying bouts after a relatively consistent net gain in CBT of 0.40 to $0.48^{\circ} \mathrm{C}$ (Table 2). The net gain in CBT was similar across a wide range of ambient THI, bout durations, and initial CBT. These results suggest that the net increase in CBT during a lying bout is perhaps a more important determinant of when a cow stands than is an absolute threshold CBT.

Part of the explanation of the shorter duration of lying bouts under heat stress conditions may be found in the rates of change of CBT within bouts. We found that cows accumulate $\mathrm{CBT}$ at a mean rate of $+0.50^{\circ} \mathrm{C} / \mathrm{h}$ while lying in freestalls supplemented with fans in heat stress conditions. Our results are very similar to the $+0.59^{\circ} \mathrm{C} / \mathrm{h}$ gain found by Hillman et al. (2005) for heatstressed cows lying in freestalls with fans. Although our overall mean rate of $\mathrm{CBT}$ gain was $+0.50^{\circ} \mathrm{C} / \mathrm{h}$, the increase was as low as $0.28^{\circ} \mathrm{C} / \mathrm{h}$ during extended lying bouts at low $\mathrm{THI}$ and as great as $0.76^{\circ} \mathrm{C} / \mathrm{h}$ during shortened lying bouts at high THI (Table 2). Starting at the same CBT, cows will reach hyperthermia $\left(>39.0^{\circ} \mathrm{C}\right)$ more quickly at a higher starting THI than at a lower starting THI.

Whereas cows increase CBT when lying down during periods of heat stress, the rate of gain would be modified by local conditions affecting both convection and conduction while lying in the freestall. High velocity air moving over the surface of the lying cow will enhance cooling due to convection and evaporation (Fournel et al., 2017). In the barns in this study, the single row of fans directed slightly downward toward the cows in the head-to-head stalls were spaced at 12.5 $\mathrm{m}$, and the actual air velocity at the cow level would diminish inversely with the distance from each fan and vary from stall to stall. Conduction of heat away from the lying cow can occur because approximately $20 \%$ of the surface area of the cow is in contact with the stall bedding (Ortiz et al., 2015). Studies on differences in thermal conductivity of various bedding materials are quite limited, but dried manure bedding as used in the barns in our study is associated with higher CBT than sand, especially in hot humid climates (Ortiz et al., 2015).

\section{Standing Thermodynamics in Freestall Pens and Holding Pens}

Whereas we found that cows dissipated heat at an overall mean rate of $-0.25^{\circ} \mathrm{C} / \mathrm{h}$ when standing in the freestall pens, Hillman et al. (2005) reported a greater rate of -0.59 to $-0.75^{\circ} \mathrm{C} / \mathrm{h}$ standing under feed line soakers and fans. The same study by Hillman et al. (2005) showed that cows neither gained nor lost CBT standing under fans without soakers. The cows in our study could have been standing either under sprinklers or in freestalls under fans or in alleys without either sprinklers or fans, so the intermediate value appears consistent with the Hillman et al. (2005) study and the understanding that the combination of sprinklers and supplemental airflow is more effective for heat dissipation than either fans or sprinkling alone (Collier et al., 2006).

Although the overall mean heat dissipation rate of $-0.25^{\circ} \mathrm{C} / \mathrm{h}$ was relatively modest, the rate at different THI points was remarkably varied as shown in Table 4. Cows dissipated CBT at a greater rate when THI was 75 or below, but cows actually increased CBT while standing at THI 80 and above. Although the standing bout duration was relatively short at approximately 50 min at the lower THI points, the bouts were twice as long (102 min) at THI 85. Clearly, some cows stood for extended periods without dissipating CBT, and perhaps the behavioral decision to lie down reflects an affective state of fatigue, discomfort, or frustration more than factors related to CBT (Polsky and von Keyserlingk, 2017).

Cows standing in the holding pen dissipated heat at only $-0.09^{\circ} \mathrm{C} / \mathrm{h}$. Although Collier et al. (2006) suggested that holding pens are the location where dairy cows experience the greatest heat stress on a dairy, the current study is the first to our knowledge to report rate of CBT change in this location. Collier et al. (2006) made a case for the installation of soakers and fans as a method to reduce heat stress in the holding pens; however, both holding pens in our study were 
equipped with this cooling technology at current recommended standards (Smith et al., 2006) and still had relatively poor heat dissipation. Further, both holding pens in the current study were stocked at a maximum density of $2 \mathrm{~m}^{2}$ per cow, which is a substantially more ample area per cow than the standard of $1.4 \mathrm{~m}^{2}$ per cow recommended by Smith et al. (1997). Our study confirms that holding pens are a site of considerable heat stress for lactating cows and suggests that cow cooling needs to be enhanced in parlor holding pens in modern confinement dairy facilities.

Although many other factors are involved, standing and lying behavior under heat stress conditions appears to be partially a balance between rate of CBT gain while lying and dissipation rate while standing. The overall rate of $\mathrm{CBT}$ increase while lying was double the rate of decrease while standing in the freestall pen, so cows would stand approximately twice as long as they lie down to maintain homeostatic CBT. Supporting that general relationship, the overall daily standing and lying times were approximately 16 and $8 \mathrm{~h} / \mathrm{d}$, respectively, throughout this study. Dairy cows follow a relatively consistent milking order from day to day (Beggs et al., 2018), and in the cows included in this study, total daily time standing in the holding pens ranged from approximately 30 to $160 \mathrm{~min} / \mathrm{d}$. Therefore, the effect of minimal heat dissipation in the holding pens will likely have a greater effect on the cows falling to the end of the milking order.

The minimal CBT dissipation in the holding pens in this study should be the focus of further study and potential innovation to enhance cooling in this important area.

\section{CONCLUSIONS}

Studies investigating the behavioral effects of ambient THI and heat stress are challenging to perform, and it is notable how few are reported in the peer-reviewed literature. This study took advantage of an opportunity to examine the effect of elevated environmental THI associated with a heat wave on a group of cows matched for parity, DIM, and milk yield. However, the current study lacked repetition at fixed THI levels, and future studies are necessary to confirm these findings under more controlled circumstances where repeated observations can be made. The study helps to clarify strategies for minimizing the adverse effects of heat stress on dairy cows. The CBT gains demonstrated in this study while lying could potentially be mitigated through convection from more uniform and adequate air velocity over the cows resting in the stalls and by increasing conductivity into bedding. Heat exchangers using circulating water covered with bedding have been studied. We identified modern holding pens equipped with sprinklers and fans as a location for needed improvements in heat dissipation. Potential areas for improvement may include precooling of air going into the holding pen, minimizing the recycling of air within the holding pen, altering the angle and velocity of airflow, increasing the sprinkler uniformity and volume across the holding pen, and the use of cooling showers in the exit lane or in separate pens away from the milking parlor. Any strategies that increase CBT dissipation in the holding pen and reduce CBT gains while lying in the freestalls should reduce daily standing time and potentially improve productivity and welfare.

\section{ACKNOWLEDGMENTS}

The authors thank Bob Nagel, herd manager, and his staff at the 2 dairies (northeastern Wisconsin) for assistance and cooperation throughout this trial. We also thank Nicholas Keuler of the College of Agriculture and Life Sciences Statistical Consulting Service (University of Wisconsin-Madison) for advice about the analysis of data. We thank Christopher Y. Choi and Mario Mondaca of the Department of Biological Systems Engineering at the University of Wisconsin-Madison for development of a prototype positive pressure ventilation tube prior to installation in the holding pen on one of the dairies. The authors thank Zoetis Animal Health (Florham Park, NJ) for providing blank CIDR devices for vaginal insertion of the temperature loggers. This study was funded in part by the Dairyland Initiative (https://thedairylandinitiative.vetmed.wisc.edu/), which receives financial support from the Professional Dairy Producers of Wisconsin Foundation, Dean Foods Foundation, Saputo, Zoetis, Zinpro Corporation, Save Cows Symposium, DeLaval, Nutreco, and 4dBarn. Peter A. Strassburg was funded by the Veterinary Summer Scholars program (University of Wisconsin-Madison) in 2013.

\section{REFERENCES}

Allen, J. D., L. W. Hall, R. J. Collier, and J. F. Smith. 2015. Effect of core body temperature, time of day, and climate conditions on behavioral patterns of lactating dairy cows experiencing mild to moderate heat stress. J. Dairy Sci. 98:118-127. https://doi.org/10 .3168/jds.2013-7704.

Armstrong, D. 1994. Heat stress interaction with shade and cooling. J. Dairy Sci. 77:2044-2050. https://doi.org/10.3168/jds.S0022 $-0302(94) 77149-6$.

Beggs, D. S., E. C. Jongman, P. H. Hemsworth, and A. D. Fisher. 2018. Milking order consistency of dairy cows in large Australian herds. J. Dairy Sci. 101:603-608. https://doi.org/10.3168/jds.2017 -12748 .

Bohmanova, J., I. Misztal, and J. B. Cole. 2007. Temperature-humidity indices as indicators of milk production losses due to heat stress. J. Dairy Sci. 90:1947-1956. https://doi.org/10.3168/jds.2006-513. 
Chapinal, N., A. M. De Passille, D. M. Weary, M. A. G. von Keyserlingk, and J. Rushen. 2009. Using gait score, walking speed, and lying behavior to detect hoof lesions in dairy cows. J. Dairy Sci. 92:4365-4374. https://doi.org/10.3168/jds.2009-2115.

Collier, R. J., G. E. Dahl, and M. J. VanBaale. 2006. Major advances associated with environmental effects on dairy cattle. J. Dairy Sci. 89:1244-1253. https://doi.org/10.3168/jds.S0022-0302(06)72193 -2 .

Collier, R. J., B. J. Renquist, and Y. Xiao. 2017. A 100-year review: Stress physiology including heat stress. J. Dairy Sci. 100:1036710380. https://doi.org/10.3168/jds.2017-13676.

Collier, R. J., R. B. Zimbelman, R. P. Rhoads, M. L. Rhoads, and L. H. Baumgard. 2011. A re-evaluation of the impact of temperature humidity index (THI) and black globe humidity index (BGHI) on milk production in high producing dairy cows. Pages $113-125$ in Proc. Western Dairy Manage. Conf., Reno, NV. Accessed Sep. 15, 2015. http://www.wdmc.org/2011/2011\%20Proceedings-Complete .pdf.

Cook, N. B., R. L. Mentink, T. B. Bennett, and K. Burgi. 2007. The effect of heat stress and lameness on time budgets of lactating dairy cows. J. Dairy Sci. 90:1674-1682. https://doi.org/10.3168/ jds.2006-634.

Cook, N. B., K. V. Nordlund, and G. R. Oetzel. 2004. Environmental influences on claw horn lesions associated with laminitis and subacute ruminal acidosis in dairy cows. J. Dairy Sci. 87(E-Suppl.):36-46. https://doi.org/10.3168/jds.S0022-0302(04)70059-4.

Dahl, G. E., S. Tao, and A. P. A. Monteiro. 2016. Effects of lategestation heat stress on immunity and performance of calves. J. Dairy Sci. 99:3193-3198. https://doi.org/10.3168/jds.2015-9990.

Drissler, M., M. Gaworski, C. B. Tucker, and D. M. Weary. 2005. Freestall maintenance: Effects on lying behavior of dairy cattle. J. Dairy Sci. 88:2381-2387. https://doi.org/10.3168/jds.S0022 -0302(05)72916-7.

Fournel, S., V. Ouellet, and E. Charbonneau. 2017. Practices for alleviating heat stress of dairy cows in humid continental climates: A literature review. Animals (Basel) 7:37.

Fregonesi, J. A., C. B. Tucker, and D. M. Weary. 2007a. Overstocking reduces lying time in dairy cows. J. Dairy Sci. 90:3349-3354. https: //doi.org/10.3168/jds.2006-794.

Fregonesi, J. A., D. M. Veira, M. A. G. von Keyserlingk, and D. M Weary. 2007b. Effects of bedding quality on lying behavior of dairy cows. J. Dairy Sci. 90:5468-5472. https://doi.org/10.3168/jds.2007 -0494 .

Galindo, F., and D. M. Broom. 2000. The relationships between social behaviour of dairy cows and the occurrence of lameness in three herds. Res. Vet. Sci. 69:75-79. https://doi.org/10.1053/rvsc.2000 .0391 .

Galindo, F., D. M. Broom, and P. G. G. Jackson. 2000. A note on possible link between behaviour and the occurrence of lameness in dairy cows. Appl. Anim. Behav. Sci. 67:335-341. https://doi.org/ 10.1016/S0168-1591(99)00114-8.

Gomez, A., and N. B. Cook. 2010. Time budgets of lactating dairy cattle in commercial freestall herds. J. Dairy Sci. 93:5772-5781. https://doi.org/10.3168/jds.2010-3436.

Haley, D. B., J. Rushen, and A. M. de Passillé. 2000. Behavioural indicators of cow comfort: Activity and resting behaviour of dairy cows in two types of housing. Can. J. Anim. Sci. 80:257-263. https: //doi.org/10.4141/A99-084.

Hillman, P. E., C. N. Lee, and S. T. Willard. 2005. Thermoregulatory responses associated with lying and standing in heat-stressed dairy cows. Trans. ASAE 48:795-801. https://doi.org/10.13031/ 2013.18322 .

Ito, K., D. M. Weary, and M. A. G. von Keyserlingk. 2009. Lying behavior: Assessing within- and between-herd variation in free-stallhoused dairy cows. J. Dairy Sci. 92:4412-4420. https://doi.org/10 $.3168 /$ jds.2009-2235.

Jordan, E. R. 2003. Effects of heat stress on reproduction. J. Dairy Sci. 86:E104-E114. https://doi.org/10.3168/jds.S0022-0302(03)74043 -0 .

Ledgerwood, D. N., C. Winckler, and C. B. Tucker. 2010. Evaluation of data loggers, sampling intervals, and editing techniques for measuring the lying behavior of dairy cattle. J. Dairy Sci. 93:5129 5139. https://doi.org/10.3168/jds.2009-2945.

Leonard, F. C., J. M. O'Connell, and K. J. O'Farrell. 1996. Effect of overcrowding on claw health in first-calved Friesian heifers. Br. Vet. J. 152:459-472. https://doi.org/10.1016/S0007-1935(96)80040-6.

Mentink, R. L., and N. B. Cook. 2006. Feed bunk utilization in dairy cows housed in pens with either two or three rows of free stalls. J. Dairy Sci. 89:134-138. https://doi.org/10.3168/jds.S0022 -0302(06)72076-8.

Mondaca, M. R., C. Y. Choi, N. Cook, and K. Nordlund. 2013a. Evaluation of positive pressure air distribution systems for dairy housing. Pages 1-7 in Annu. Int. Meet. Am. Soc. Agric. Biol. Eng., Kansas City, MO. Am. Soc. Agric. Biol. Eng., St. Joseph, MI. https://doi.org/10.13031/aim.20131598624.

Mondaca, M. R., F. Rojano, K. Gebremedhin, and C. Y. Choi. 2013b. A conjugate heat and mass transfer model to evaluate the efficiency of conductive cooling for dairy cattle. Trans. ASABE 56:1471-1482. https://doi.org/10.13031/trans.56.10178.

Morabito, E., H. W. Barkema, E. A. Pajor, L. Solano, D. Pellerin, and K. Orsel. 2017. Effects of changing freestall area on lameness, lying time, and leg injuries on dairy farms in Alberta, Canada. J. Dairy Sci. 100:6516-6526. https://doi.org/10.3168/jds.2016-12467.

NRC. 1971. A Guide to Environmental Research on Animals. Natl Acad. Sci., Washington, DC.

NRC. 2001. Nutrient Requirements of Dairy Cattle. 7th rev. ed. Natl Acad. Press, Washington, DC.

Ortiz, X. A., J. F. Smith, F. Rojano, C. Y. Choi, J. Bruer, T. Steele, N. Schuring, J. Allen, and R. J. Collier. 2015. Evaluation of conductive cooling of lactating dairy cows under controlled environmental conditions. J. Dairy Sci. 98:1759-1771. https://doi.org/10 $.3168 /$ jds.2014-8583.

Polsky, L., and M. A. G. von Keyserlingk. 2017. Invited review: Effects of heat stress on dairy cattle welfare. J. Dairy Sci. 100:8645-8657. https://doi.org/10.3168/jds.2017-12651.

Proudfoot, K. L., D. M. Weary, and M. A. G. Von Keyserlingk. 2010 Behavior during transition differs for cows diagnosed with claw horn lesions in mid lactation. J. Dairy Sci. 93:3970-3978. https:// doi.org/10.3168/jds.2009-2767.

Schüller, L. K., O. Burfeind, and W. Heuwieser. 2013. Comparison of ambient temperature, relative humidity, and temperature-humidity index between on-farm measurements and official meteorological data. J. Dairy Sci. 96:7731-7738. https://doi.org/10.3168/jds .2013-6736.

Schüller, L. K., O. Burfeind, and W. Heuwieser. 2016. Effect of shortand long-term heat stress on the conception risk of dairy cows under natural service and artificial insemination breeding programs. J. Dairy Sci. 99:2996-3002. https://doi.org/10.3168/jds .2015-10080

Schüller, L. K., and W. Heuwieser. 2016. Measurement of heat stress conditions at cow level and comparison to climate conditions at stationary locations inside a dairy barn. J. Dairy Res. 83:305-311. https://doi.org/10.1017/S0022029916000388.

Smith, J. F., D. V. Armstrong, M. J. Gamroth, and J. G. Martin. 1997. Planning the milking center in expanding dairies. J. Dairy Sci. 80:1866-1871. https://doi.org/10.3168/jds.S0022-0302(97)76122 $-8$

Smith, J. F., M. J. Brouk, J. P. Harner III, and K. C. Dhuyvetter. 2006. Issues with dairy facilities located in the high plains. Pages 1-13 in Proc. High Plains Dairy Conf., Albuquerque, NM. Texas Animal Nutrition Council, Champaign, IL.

Solano, L., H. W. Barkema, E. A. Pajor, S. Mason, S. J. LeBlanc, C G. R. Nash, D. B. Haley, D. Pellerin, J. Rushen, A. M. de Passillé, and E. Vasseur. 2016. Associations between lying behavior and lameness in Canadian Holstein-Friesian cows housed in freestall barns. J. Dairy Sci. 99:2086-2101. https://doi.org/10.3168/jds 2015-10336.

St-Pierre, N. R., B. Cobanov, and G. Schnitkey. 2003. Economic losses from heat stress by US livestock industries. J. Dairy Sci. 86:E52E77. https://doi.org/10.3168/jds.S0022-0302(03)74040-5.

Tao, S., R. M. Orellana, X. Weng, T. N. Marins, G. E. Dahl, and J. K. Bernard. 2018. The influences of heat stress on bovine mam- 
mary gland function. J. Dairy Sci. 101:5642-5654. https://doi.org/ 10.3168/jds.2017-13727.

Terra, R. L., and J. P. Reynolds. 2014. Ruminant history, physical examination, welfare assessment, and records. Pages 2-12 in Large Animal Internal Medicine. 5th ed. B. P. Smith, ed. Elsevier Mosby, St. Louis, MO.

Thompson, A. J., D. M. Weary, and M. A. G. von Keyserlingk. 2017. Mining data from on-farm electronic equipment to identify the time dairy cows spend away from the pen. J. Dairy Sci. 100:39753982. https://doi.org/10.3168/jds.2016-11713.

Tucker, C. B., and D. M. Weary. 2004. Bedding on geotextile mattresses: How much is needed to improve cow comfort? J. Dairy Sci. 87:2889-2895. https://doi.org/10.3168/jds.S0022-0302(04)73419 -0 .

Tucker, C. B., D. M. Weary, and D. Fraser. 2003. Effects of three types of free-stall surfaces on preferences and stall usage by dairy cows. J. Dairy Sci. 86:521-529. https://doi.org/10.3168/jds.S0022 -0302(03)73630-3.

Tucker, C. B., D. M. Weary, and D. Fraser. 2004. Free-stall dimensions: Effects on preference and stall usage. J. Dairy Sci. 87:12081216. https://doi.org/10.3168/jds.S0022-0302(04)73271-3.
Vasseur, E., J. Gibbons, J. Rushen, D. Pellerin, E. Pajor, D. Lefebvre, and A. M. de Passillé. 2015. An assessment tool to help producers improve cow comfort on their farms. J. Dairy Sci. 98:698-708. https://doi.org/10.3168/jds.2014-8224.

Vasseur, E., J. Rushen, D. B. Haley, and A. M. de Passillé. 2012. Sampling cows to assess lying time for on-farm animal welfare assessment. J. Dairy Sci. 95:4968-4977. https://doi.org/10.3168/ jds.2011-5176.

Vickers, L. A., O. Burfeind, M. A. G. von Keyserlingk, D. M. Veira, D. M. Weary, and W. Heuwieser. 2010. Comparison of rectal and vaginal temperatures in lactating dairy cows. J. Dairy Sci. 93:5246-5251. https://doi.org/10.3168/jds.2010-3388.

von Keyserlingk, M. A. G., A. Barrientos, K. Ito, E. Galo, and D. M. Weary. 2012. Benchmarking cow comfort on North American freestall dairies: Lameness, leg injuries, lying time, facility design, and management for high-producing Holstein dairy cows. J. Dairy Sci. 95:7399-7408. https://doi.org/10.3168/jds.2012-5807.

West, J. W. 2003. Effects of heat-stress on production in dairy cattle. J. Dairy Sci. 86:2131-2144. https://doi.org/10.3168/jds.S0022 $-0302(03) 73803-\mathrm{X}$. 